\title{
Pandilla 18 y Mara Salvatrucha 13: violencia y desciudadanización
}

\author{
Pandilla 18 and Mara Salvatrucha 13 Street Gangs: Violence and \\ Decitizenization
}

\author{
HUGO MORENO HERNÁNDEZ \\ Universidad Iberoamericana, México \\ MÓNICA SÁNCHEZ GONZÁLEZ \\ Universidad Iberoamericana, México
}

RECEPCIÓN: 6/6/20I2 ACEPTACIÓN: 27/II/20I2

RESUMEN El presente trabajo es parte de una investigación sobre formas de reestratificación desde la sociedad civil. Aquí se observan las estrategias institucionales para el tratamiento del fenómeno de las pandillas transnacionales llevadas a cabo en El Salvador. Se observa cómo estas estrategias producen mayor violencia, sin presentar opciones organizativas orientadas a mejorar la vida de los jóvenes pandilleros, sin buscar crear formas sociales productivas en el sentido de asegurar a los jóvenes marginales instancias de resistencia a los influjos del sistema capitalista que los excluye. En estos términos, se propone observar las estrategias gubernamentales y sus efectos en la transformación de las pandillas hacia formas más violentas y jerarquizadas, debido a la acción criminalizante de las instituciones del gobierno. Así pues, se propone la observación de la reestratificación institucional de las pandillas, mediante la criminalización y su asimilación al crimen organizado, como elemento que ha producido una tendencia a la jerarquización, la clandestinidad y el aumento de la violencia.

PALABRAS CLAVE Pandillas transnacionales, criminalización de la juventud, leyes de excepción, violencia juvenil. 
ABSTRACT The present work is part of research into forms of re-stratification from the angle of civil society. Here we observe the institutional strategies applied to deal with the phenomenon of multi-national street gangs in El Salvador. We observe how these strategies produce greater violence, without offering organizational options oriented towards improving the lives of the young gang-members, and without seeking to create productive social forms which will give these marginalized youths opportunities to resist the inflows of the capitalist system from which they are excluded. In these terms, we propose to observe government strategies and their effects on the transformation of the gangs towards more violent and hierarchized forms, due to the criminalizing actions of government institutions. Thus we propose to observe the institutional re-stratification of the gangs through criminalization and their assimilation to organized crime as an element which has produced a tendency towards hierarchization, clandestinity and increased violence.

KEYWORDS Multi-national gangs, criminalization of young people, exception laws, juvenile violence.

\section{Asimilación de las pandillas transnacionales a crimen organizado}

La asimilación realizada por gobiernos y agencias de seguridad entre las pandillas transnacionales de cultura angelina (del West Side y sureñas, distintas de otras formas como los Latin Kings), específicamente la Pandilla o Barrio I 8 y la Mara Salvatrucha I3, a formas de crimen organizado y narcotráfico, se ha convertido en la principal operación de análisis y observación para el tratamiento del fenómeno por parte de las instancias gubernamentales. El tratamiento policiaco coloca a las pandillas del mismo lado que el narcotráfico, el tráfico de armas y personas, incluso no sólo como parte de las economías criminales transnacionalizadas (globalizadas), sino como fuerza líder del narcotráfico regional. La manera de asir el fenómeno moviliza estrategias puramente criminalizadoras, con perspectiva exclusivamente policial. Cerrando las diversas vías de comunicación con los jóvenes para instaurar un acercamiento concentrado en la policía y la ley como la vías predilectas de los gobiernos para construir referentes institucionales a los jóvenes inscritos en pandillas, es decir, ley, cárcel y persecución son las fuerzas sociales con que los Estados se relacionan con este sector y los jóvenes, reducidos a delincuentes, reducen al resto de la sociedad a su función policiaca. 
El primer problema al que se enfrenta esta asimilación de las pandillas con el crimen organizado es al nivel de la participación de las pandillas en la economía de las drogas, pues al asumir cierto liderazgo de estos grupos, en primer lugar, no se observa la complejidad del fenómeno y, en segundo, no se combate eficientemente el narcotráfico, pues, como han observado Jeannette Aguilar y Marlon Carranza (2009), «la participación actual de las pandillas en el tráfico de drogas se limita al narcomenudeo o al control de los pequeños mercados domésticos de drogas y no al tráfico regional o a las redes de tráfico más sofisticadas como han insistido algunos funcionarios gubernamentales» (I38). Si bien entre pandillas y crimen organizado suceden alianzas, éstas no vertebran las dinámicas y rutinas de las pandillas, pues la estructura criminal utiliza a los jóvenes para cuestiones muy localizadas o de bajo perfil respecto a la organización ilegal de la producción y trasiego de cantidades importantes. La pandilla es un cuerpo sin órganos:

La pandilla no es un organismo, es una desestratificación del cuerpo de la sociedad, porque «deshacer el organismo nunca ha sido matarse, sino abrir el cuerpo a conexiones que suponen todo un agenciamiento, circuitos, conjunciones, niveles y umbrales, pasos y distribuciones de intensidad, territorios y desterritorializaciones medidas a la manera de un agrimensor», un rizoma, lugar sin centro, sin jerarquía. Un rizoma es, ante todo, una tendencia de las fuerzas relacionadas hacia la horizontalidad. Ese es el asunto por el cual las pandillas transnacionales no pueden ser atrapadas con su asimilación a organizaciones criminales, ni siquiera si se consideran órganos del crimen organizado, pues su participación o es a título de individualidad o en términos de un agenciamiento, de una conexión con el crimen organizado en cuanto parte del resto de la sociedad (Moreno y Sánchez, 20I2: 77).

De la misma manera distingue la Oficina contra la Droga y el Delito de Naciones Unidas a las pandillas, incluso las que denomina «institucionalizadas», de las organizaciones criminales (ONU 2007: 63-64). El delito, si bien es parte de las rutinas pandilleras, no coagula al grupo. Al carecer de estratificación organizativa, la capacidad de las pandillas (por más institucionalizadas, como señala el informe de la ONU, es decir, por más que hayan alcanzado formas que exceden el territorio a través del nombre y la lealtad al barrio extendido más allá de las fronteras y el tiempo) de alcanzar los niveles de sofisticación de las 
organizaciones criminales resulta, por lo menos, inverosímil, según los recursos materiales y de inteligencia con los que cuentan los cárteles de la droga. Los jóvenes que integran las pandillas carecen de capacidades estratégicas para disputarle a los cárteles el control del mercado ilegal de drogas, que va desde la producción, transporte, distribución a granel y narcomenudeo. En esta última etapa es donde los pandilleros se integran a la organización criminal; en el otro extremo, en el de la producción, están los campesinos, integrados marginalmente en la estructura organizativa de los cárteles, pero eso no los convierte en una fuerza que se dispute el control de los ingresos del mercado ilegal de la droga. La manera en que los jóvenes se integran a la estructura es tan marginal como la de los productores agrícolas. Esta condición marginal se empalma con la condición etaria. No es inútil mantener en mente que en su mayoría son jóvenes los miembros de las pandillas transnacionales y que el tilde «transnacional» se refiere a la desterritorialización forzada por migración y deportación, es decir, no como una estrategia de expansión mercantil, sino como un fenómeno que arrecia y petrifica la condición marginal de los pandilleros, convirtiendo a la pandilla en un lugar/social comunitario:

Las pandillas como la i 8 y la MS (transnacionales) son lugares sociales/comunitarios desterritorializados operando una reterritorialización desmarcada, es decir, construyen territorio en el espacio líquido, enrarecido, telúrico que les ofrece la desterritorialización del capitalismo contemporáneo. Lo realizan en un contraflujo, en coagulaciones agresivas y explosivas, con cualidades perfectas para llegar a la violencia (Moreno y Sánchez, 20I2: 78).

La condición marginal de las pandillas respecto al resto de la sociedad implica al crimen organizado como parte de su entorno, como parte de lo que no son y les constituye. Por esto, la asimilación al crimen organizado de las pandillas transnacionales es un error garrafal para la observación y comprensión de la complejidad que envuelve al fenómeno de las pandillas transnacionales. Los pandilleros son marginados en las estructuras de las organizaciones criminales, son empleados e, incluso, herramientas, orbitan pero no son parte de la estructuras. El ya citado informe de la onU, Crimen y desarrollo en Centroamérica. Atrapados en una encrucijada, destaca esta posición orbital de los pandilleros respecto a la fuerza de gravedad de las organizaciones criminales altamente sofisticadas en lo que concierne al narcomenudeo, transportación local e interna- 
cional por medios terrestres y marítimos (2007: 62-7I). El siguiente testimonio refuerza el argumento:

Uta, eso es una... sí es un peligro porque las condiciones económicas del país, bueno, estamos padeciendo desempleo del 62, no perdón, del $64,7 \%$, somos casi 7 millones de salvadoreños y si tenemos un desempleo del $64,7 \%$, más de la mitad está desempleada en El Salvador, ahora, si estás desempleado y tenemos un alto consumismo, porque somos un pinche país consumista, no tenemos pero consumimos, entonces, vienen, digo yo, los Zetas por ahí, tu ya tienes cinco, seis meses que ya te van a quitar hasta tu casa güey, y te dicen te voy a regalar 500 dólares semanales güey, porque me tengás una cuenta abierta, porque hagás esto, porque hagás esto otro, de los 64,7 que están sin trabajo, quién putas crees que no va a recibir una oferta de ésas, que vive en una, o sea, se vuelve controversial porque realmente te vuelves como trabajadores de ellos, pero porque realmente estás pasando una pinche vida social.

En lo expuesto, queda claro que las condiciones económicas de El Salvador implican a todos los sectores pauperizados de la población. La desigualdad económica agudiza las condiciones de marginación. Sin embargo, no es posible imponer un desemboque lógico pobreza-delincuencia organizada. De ahí que el testimonio identifique un peligro específico para los pandilleros, quienes, en primer instancia, serían los elementos buscados por las estructuras del crimen organizado para ser reclutados:

Ahora, algo que sí te puedo decir y que está bien demostrado, es que un pandillero nunca va a llegar a estar en los estatus de las mafias, por qué, porque no sé, nunca se ha podido, si un pinche pandillero empieza a manejar más de tres o cuatro kilos de cocaína lo matan, lo encierran o lo chingan, porque ya lleva mucho poder. Lo utilizan como narcomenudeo nada más, toma dos kilos véndelos güey, agarra tu cancha y me das mi billete. Y los pueden utilizar para un sinfín de cosas, qué sé yo. Pero esto no porque en realidad quieran meterse o porque realmente quieran hacer una mafia o porque querer, no. Es porque las condiciones económicas de este país no permiten más que empezar a delinquir, te empujan a delinquir.

La posición del pandillero, como se dijo, queda localizada en los márgenes, incluso en las estructuras de la economía subterránea y en las organizaciones 
delincuenciales su posición está al fondo del escalafón, ahí donde los elementos son fácilmente intercambiables, donde no hay posibilidad de dominar, para decirlo con Bourdieu, un campo (el campo criminal, si se quiere). Es, incluso, demasiado complicado entenderlos como una clase en el campo luchando contra el centro que le estructura. Los pandilleros son simples elementos de uso y consumo para fines más, digamos, «elevados» de la estructura criminal:

Pero ni un pandillero ha llegado, bueno, cada vez que agarran, los pinches narcobarriles con millonadas de, eran civiles, en los barcos que han agarrado coca, que han agarrado barcos llenos de coca en El Salvador, eran civiles. Civiles es que era persona normal, nosotros llamamos civiles a los demás. Entonces, nunca he visto a un pinche pandillero ahí, inclusive ahorita están agarrando a los coyotes que sirvieron para agarrar a los que fueron y los mataron allá en Tamaulipas, no hay ni un pandillero. Todos son personas de la sociedad civil, no ha habido ni un pandillero. $\mathrm{Y}$ en realidad es muy difícil que un pandillero, por las características también.

En entrevistas con pandilleros calmados y activos en El Salvador se les preguntó sobre las actividades delincuenciales realizadas por la pandilla como forma articuladora del grupo, específicamente si existían vínculos orgánicos con las estructuras del crimen organizado internacional. M., un pandillero calmado, distingue claramente a la pandilla del delito simple y llano:

Lo primero no es lo malo que se hace. Lo malo que podás hacer dentro de la pandilla es lo que va determinar tu jerarquía al interior de la pandilla. Ser un pandillero no es malo, malo es lo que uno comete. No necesitás ser un delincuente para ser un pandillero. Delinquís por pura necesidá o por gusto, el gusto de un placer, pero una cosa de ser pandillero y delincuente no es relativo a nada. Cualquiera dice que roba por necesidad. En el caso de las pandillas, se determina su peligrosidad por su agresividad, son peligrosas porque son agresivas, matan a la gente y no sólo la matan, la descuartizan, la desaliñan, la secuestran y la torturan. No sé. Pienso de que es un calificativo que lo han ocupado las mafias, los cárteles, los ejércitos y sicópatas. Han utilizado, pienso de que no es... y con eso no le estoy justificando nada, pero pienso que no es un comportamiento exclusivo, no es exclusivo.

La forma de la violencia (decapitaciones, mutilaciones, formas espeluznan- 
tes que buscan crear marcadores territoriales y enviar comunicaciones claras a los adversarios) se ha recrudecido en El Salvador en la década del 2000, sobre todo debido al influjo de las legislaciones criminalizantes. La reclusión de los pandilleros participó de manera central en la conformación de jerarquías más rígidas tanto en la Pandilla i 8 como en la MS13. Esto mismo, para el caso de la 18, produjo un sisma dejando dos bandos enfrentados y ha provocado demasiada violencia como para vislumbrar una recomposición. Si bien hay un uso de formas que pueden emparentarse con los usos de organizaciones delincuenciales, en el caso de las pandillas esto se clausura en la rivalidad mortal que las enfrenta, lo que, con el deterioro de las relaciones intrapandilla (el sisma de la I 8) expande la violencia a las localidades contra los civiles y articula «empresas» delincuenciales (como la extorsión) destinadas a conseguir el fin último y vertebral del grupo, su sobrevivencia:

Entonces son ese tipo de acciones... pero en las pandillas es más distinto. Es lo que vos podás pensar, vaya, si vos tenés... en tu comunidad hay cincuenta pandilleros y tú eres el líder, esas cincuenta vidas son tu responsabilidad, si uno de esos muere, posiblemente sobre ti cae, porque vos diste una mala orden, o dijiste que se hiciera algo mal, o les dijiste que tomaran y se descuidaran de su propia vida, porque el enemigo anda rondando. $\mathrm{O}$ se drogaron porque tú les dijiste y entonces el enemigo los logró agarrar. Entonces ser pandillero o tener jerarquía no es por ser asesino, es por ver cómo hacés sobrevivir a tu pandilla en un ambiente que es hostil porque tenés a una sociedad y a un sistema de seguridad en tu contra y la misión es mantener tus soldados libres y vivos. Vivos sobreviviendo... o viviendo...

M. logra definir a la pandilla según sus condiciones como un cuerpo sin órganos, una forma desestratificada orillada a la reestratificación por criminalización. En la mismas entrevistas, el robo y la extorsión (de carácter local) se afirmaron como parte de las rutinas del grupo, asimismo, el narcomenudeo (también anclado a los territorios locales dominados por la pandilla), delitos que no se imponen a los miembros, sino que suceden en el marco de la búsqueda de recursos. De igual forma, se explicó que muchos pandilleros mantienen trabajos legales mal pagados. El delito no está fuera de las actividades pandilleriles, le atraviesa como una forma más de violencia, pero no organizan el ser de la pandilla, la reunión, el rito de pasaje (el brinco), no significan un modelo de conscripción para la delincuencia (si bien tampoco suponen su ausencia) 
y para realizar actividades vinculadas con el crimen organizado, la pandilla avala esto como si el miembro decidiera tomar un trabajo en una fábrica o call center. Sin embargo, el vínculo con el crimen organizado puede suceder a través de una clica completa, lo que no incluye a toda la pandilla en su carácter transnacional. Si bien también es claro que algunas clicas dominan el comercio de drogas en territorios específicos e, incluso, al interior de reclusorios destinados a miembros de su pandilla, como observan Carlos Martínez y José Luis Sanz en su reportaje en cinco capítulos El barrio roto (20I I), esto no los asimila a los cárteles internacionales de la droga.

Al ser consultados los pandilleros sobre la relación con las bandas criminales, el 55 por ciento en Guatemala y el I4 por ciento en El Salvador admitió sostener alguna relación con estos grupos delincuenciales. A su vez, cerca de un 40 por ciento de los entrevistados en Guatemala afirman que se trata más bien de colaboraciones personales que los pandilleros establecen con las bandas, mientras que cerca del I 4 por ciento señala un involucramiento de la clica. En el caso salvadoreño, el 6,6 por ciento de los entrevistados indicó que se trata colaboraciones de carácter personal, mientras que un porcentaje similar (6,0 por ciento) admite participación de la clica en los negocios con las bandas (Aguilar y Carranza, 2009: I39).

La aparición de pandillas transnacionales se sitúa en el marco del capitalismo de consumo y, si bien no se explica exclusivamente por la imposibilidad de habilitar a cada ciudadano como consumidor competente, sí halla en el sistema de sociedad contemporáneo, inundado por el mercado, uno de los principales detonantes. Principalmente la creación de yermos de solidaridad social. La movilidad de las pandillas, entendida en términos de instancia, más que de sujetos agrupados, es decir, más allá de la movilización de los cuerpos, sino en la expansión de formas de agregación y consecución de respeto y pertenencia, define el carácter transnacional de pandillas como el Barrio i 8, la Mara Salvatrucha I3, Latin Kings, Netas, Vatos Locos, Bloods o Crips. Las migraciones coaccionadas por el sistema económico revientan en pandillas, como ha sucedido en el caso específico de Los Ángeles, a su vez, como sucedió con la población centroamericana, sobre todo con la salvadoreña, las deportaciones masivas (proceso de doble desterritorialización), desterritorializaron a las pandillas en una expansión denominada transnacional, excediendo el espacio de la ciudad californiana. La pandilla estalló los territorios para re- 
territorializarse. Pero esto en el sentido de una pertenencia más que en el de articular una fuerza de ataque internacional con sentido criminal. Es decir, no existe un palabrero mayor cuya voz resuene en los barrios de Soyapango o en el municipio de Mejicanos en El Salvador, o en Tegucigalpa o Guatemala. La $\mathrm{MS}_{\text {I } 3}$ o el Barrio I 8 funcionan rizomáticamente, desestratificadamente, sin una jerarquía rígida. Incluso, cuando esto sucedió, con el caso del Viejo Lin en El Salvador, convirtiéndose en el portador de la palabra de todos los dieciocheros, jerarquizando a la pandilla, los resultados repercutieron en una división violenta del Barrio i 8 y, en todo caso, no se constituyó una red internacional criminal organizada para usufructuar con los lucrativos negocios de la droga, las armas o el tráfico de personas, «de hecho, el carácter transnacional de las maras en la región se limita actualmente al ámbito de lo cultural y simbólico» (Santamaría, s/f: IO3). El carácter transnacional está dado por la desterritorialización doble que permite descodificaciones y recodificaciones al nivel simbólico y ocasiona la mutación de la pandilla tradicional (inmóvil sobre un territorio, ver Perea Restrepo, 2007; Moreno, 20I I) hacia la forma extendida del barrio como instancia desterritorializada localizable y portadora de territorio simbólico o lugar/social comunitario habitable en California, Honduras o El Salvador. La desterritorialización como ejercicio de poder o una serie de ejercicios de poder donde las relaciones políticas y económicas se ocultan en los influjos de la organización social (la migración forzada y la deportación criminalizante), produce la resistencia mediante reterritorializaciones a través de la formación de pandillas-barrio, es decir, el grupo es y hace territorio, el grupo de desterritorializados usurpa tierra, se hace visible en la calle, con la ropa, los grafitis, tatuajes, jergas y, sin duda, con violencia y actividad delincuencial. Visibilidad en el margen en busca de respeto y poder, resistencia ácida que presiona nuevas desterritorializaciones, sobre todo con la ley (deportación y encarcelamiento), movimientos que expanden, no reprimen «la transnacionalidad de las maras reside, más bien, en el poder simbólico que representa la estética de estas pandillas y en los espacios de socialización que, al igual que otras pandillas, ofrecen para cientos de jóvenes excluidos de los conectores sociales tradicionales» (Moreno, 20II: I2I). Tejer en la orfandad el terreno sobre el que se instaura el barrio, a través de lazos forjados con la pertenencia absoluta a la pandilla (Moreno, 20I0), significa adquirir rasgos distintivos respecto al resto de la sociedad; éstos suministran fuerza cohesiva, expresada en reglas básicas pero rígidas para mantener disciplina y lealtad, elementos centrales en la vida pandillera, donde el sujeto se abre al otro, al homeboy, a 
sabiendas de tener la muerte siempre cercana; por tanto la deserción y la traición suponen debilitamiento del grupo.

En la entrevista con un miembro calmado de la MS I3, al abordar el tema sobre su estatus «calmado», se le preguntó ¿tú sigues siendo pandillero?

Se puede decir que sí, todavía, en mis adentros sí. Pero de relacionarme con ellos no. ¿Nunca se puede salir de la pandilla? No. No se sale. ¿Por qué? Es la ley. Es que según la regla que está que uno no se puede salir porque puede pensar de que se va a meter a la contraria y como a veces uno oye y ve cosa, pueden decirle ey este nos va, le va a decir a otro y otro le va a decir a la pandilla que vamos a hacer esto lo otro. Entonces la única forma de salir de ahí es que lo maten a uno. O sea quiérase o no siempre sale uno muerto, esté o no, o sea, por el contrario o por la misma mara.

Igualmente, se hizo el mismo cuestionamiento a un miembro de la Pandilla I 8: ¿'sigues siendo pandillero? «Es que seguís siendo pandillero».

Cuando los pandilleros hablan de hacer algo bueno por su pandilla se refieren a fortalecerla con territorios y aumento de los miembros. Hacerse más visibles, rayar las paredes y la piel para gritar su retiro de la sociedad y expandirse al interior de la pandilla. Las pandillas transnacionales logran esto mediante el nombre del grupo (Mara Salvatrucha I3, Pandilla I 8), la adhesión y lealtad a números o letras y el odio profundo a los contrarios, la guerra a muerte al rival, fuente de la violencia más grotesca en que se enfrascan las pandillas, más allá del control de plazas o vías de tráfico (a la usanza de los cárteles mexicanos), más allá del lucro está la venganza por una afrenta convertida en arcano. Cuando se pregunta el por qué de la rivalidad mortal entre pandillas, los más viejos se remiten a Los Ángeles, los más jóvenes ni se lo preguntan. El origen de la rivalidad se ha perdido entre baños de sangre y odios salvajes.

La rivalidad entre la MS I 3 y la I 8 creció y se arreció en el territorio salvadoreño, donde no existen resquicios para entablar treguas. Ni la cárcel, como sucede en territorio estadounidense. Los centros penales salvadoreños se convirtieron en espacios de enfrentamiento y muerte cuando las pandillas coexistían y no dejaron de serlo cuando los pandilleros cohabitaron con reos comunes, como ellos mismos llaman a los demás presos (la masacre de 2004 en Mariona fue el impulsor para decidir establecer centros penales exclusivos para pandilleros según su filiación). El acelerado aumento de homicidios a nivel patológico impuso una visión gubernamental puramente reactiva a tra- 
Cuadro 1. Deportaciones de Estados Unidos hacia Centroamérica de 1998 a 2007

\begin{tabular}{|lcc|}
\hline País & Deportados de 1992 a 1996* & Deportados de 1998 a 2004* \\
\hline Guatemala & 7276 & 64312 \\
\hline Honduras & 9497 & 106826 \\
El Salvador & 9767 & 87031 \\
Nicaragua & 1585 & 7745 \\
\hline
\end{tabular}

Cuadro tomado de Santamaría, s/f: 123.

vés de la cárcel y la ley, sin buscar combatir la violencia, sino combatir a las pandillas consideradas el nuevo semillero de asesinos, como antes fueran los idealistas beligerantes, siempre jóvenes. Con las políticas criminalizantes los rasgos simbólicos que definen a las pandillas mediante su visibilización ruda, han ido diluyéndose y los códigos y normas al interior se han endurecido para asegurar la lealtad y el respeto. Originando una mutación tendiente al clandestinaje y contraria a la visibilidad característica del pandillero. Esta clandestinidad como mecanismo de defensa ante los embates policiacos gubernamentales opera una reestratificación que aumenta la violencia tanto interna como al exterior de la pandilla. Los castigos por traición y las reglas a respetar se tornan más estrictos, aumentando los asesinatos perpetrados por los mismos miembros del grupo contra aquellos considerados traidores. Las luces verdes dan paso al hacha del homeboy para eliminar a su homie:

Aunque es difícil contar con cifras que confirmen que el número de pandilleros muertos a manos de sus propios compañeros se está incrementando, notas periodísticas publicadas en estos países y testimonios de los propios pandilleros, recabados en estudios recientes, señalan que las purgas internas constituyen una práctica cada vez más frecuente entre las principales pandillas centroamericanas. Una encuesta realizada en El Salvador y Guatemala encontró que 3,8\% de los encuestados en El Salvador y $3, \mathrm{x} \%$ en Guatemala atribuyen a la propia pandilla el incremento de los pandilleros muertos. Este porcentaje aumenta a I3,6\% en El Salvador cuando se analizan en forma desagregada las respuestas de los entrevistados que se consideran a sí mismos ex pandilleros, por haber desertado de la pandilla [...] En la actualidad, desertar de la pandilla es una falta castigada por lo general con la pena máxima. Sin embargo, en los reclusorios de los tres países del triángulo se ha reportado un aumento de pandille- 
ros disidentes, quienes [...] permanecen separados del resto de pandilleros para evitar ser asesinados. Aunque en términos generales estos porcentajes siguen siendo bajos, la sola existencia de esta práctica da cuenta del grado de violencia que actualmente predomina al interior de las pandillas (Aguilar y Carranza, 2009: I33).

Este aumento de la violencia intrapandilla se patentiza con la división sufrida por el Barrio i 8 en El Salvador entre Sureños y Revolución. Resultado de la intención de estratificar al Barrio i 8 a través de una cúpula de palabreros encarcelados, creando líneas de mando desde los centros penales hasta la calle, dándole la palabra sobre toda la pandilla (como se entiende el liderazgo en la Pandilla I 8) a un individuo, conocido como el Viejo Lin. Esta verticalización de la pandilla se entiende como una forma de reestratificación forzada mediante el encarcelamiento masivo iniciado a finales de los noventa y fortalecido como única forma para lidiar con el fenómeno en los años 2000, lo que aceleró el proceso de conversión de la pandilla en una fuerza beligerante, pero sin ideología política, sino articulada por la rivalidad, aumentando la violencia a niveles grotescos (como el caso Rosa N., por el que regresó el Viejo Lin a prisión), impulsando una respuesta estatal a través de leyes de excepción (en el entendido de dar un tratamiento distinto a unos ciudadanos considerados diferentes, quizá inferiores), llamadas antimaras, lo que produjo mutaciones de reestratificación de la pandilla que acrecentó la violencia tanto al exterior de la pandilla (contra los rivales y el resto de la sociedad) y al interior. Estas mutaciones incluyen un viraje a la clandestinidad, mayor desconfianza entre distintas clicas o canchas y hacia miembros considerados proclives a la traición o la falta de disciplina como las mujeres, que si bien siempre han significado un número muy inferior a los varones, con estas transformaciones ha disminuido su ingreso: «hoy la pandilla no confía mucho en la mujer. Por eso mismo, porque no tiene el valor, no tiene a veces el valor para, digamos, ir a matar a alguien, de ir a fregar a tal persona. Hoy no se siente tanto el apoyo de la mujer en la mara",

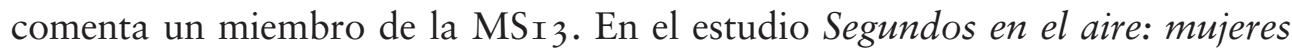
pandilleras y sus prisiones, del Instituto Universitario de Opinión Pública de la Universidad José Simeón Cañas de El Salvador, se explica que la violencia intrapandilla supone un impacto diferenciado respecto a las mujeres y que:

Con las transformaciones que ha experimentado el fenómeno de las pandillas, con la agudización de la violencia en el contexto de la imple- 
mentación de las políticas de mano dura y posterior a ese periodo, con la posición que muchos y muchas van adquiriendo con los años dentro del grupo, entre otros aspectos, la vivencia de la violencia se vuelve más brutal, más directa y más cotidiana [...] Sin embargo, cuando se trata de ataques de la propia pandilla, estos hechos conllevan impactos y significados distintos e importantes para las pandilleras: supone identificar a los miembros de esta otra «familia» como agresores; implica enfrentarse con la posibilidad -o la realidad - de sufrir la violencia a manos de quienes, en teoría, las protegerían; y lleva, en muchas ocasiones, a tomar distancia del grupo (IUDOP, 2OIO: 244-245).

En entrevista con Jeannette Aguilar, realizada en julio de 20 I I, investigadora del fenómeno de las pandillas en Centroamérica y directora del IUDOP, parte del equipo de investigación del estudio Segundos en el aire, apuntó sobre las condiciones actuales de las homegirls, en un entorno de aumento de violencia intrapandillera. "El tema de la evolución en buena medida ya la conoces y si queremos ser más acotados en términos de distinguir más el después, yo distinguiría que después de todo este proceso de corporativización del que yo hablé en Quito, en mi exposición (Se refiere a la Primera Conferencia Internacional «Más allá de las pandillas: violencias, juventudes y resistencias en el mundo globalizado", realizado en Flacso, sede Ecuador en octubre de 2010), se da durante la etapa de las manos duras, porque fueron varias». Con el concepto de «corporativización», Aguilar se refiere al aquí usado como reestratificación forzada o verticalización, que alude a la fuerza de estructuración operada por la aplicación de legislaciones criminalizantes. Aguilar continua diciendo:

El salto cualitativo de la pandilla, más estructurada, más institucionalizada, se da en ese contexto y se da fundamentalmente en las cárceles, ahí es donde van a parar muchos de los liderazgos, sin mayor control del sistema penitenciario, se organizan y logran generar nuevas pautas de funcionamiento, como el control de las actividades de las clicas en los territorios; entonces ese salto nosotros lo vimos cuando analizamos las perspectivas de evolución, fundamentalmente en el periodo 2004-2006, ahí es donde se ubica temporalmente.

En ese contexto de aumento de violencia en el periodo señalado, la condición de las mujeres pandilleras se coloca en el nivel de mayor riesgo. Aguilar explica, según las pesquisas y hallazgos de su trabajo investigativo hasta el mo- 
mento del trabajo de campo, ampliado hasta el 2008 gracias al libro Segundos en el aire, donde se recoge la perspectiva de las mujeres inmersas en las pandillas «complementada con lo que ya sabemos nos sirve para aproximarnos a la realidad interna, aunque con ellas, en los temas de la pandilla, siempre se levantan las cosas colateralmente, muchas de ellas tienen verde de la pandilla, de la propia pandilla». Es decir, están señaladas para ser asesinadas por la pandilla a la que pertenecen, lo que dificulta aún más el trabajo de investigación enfocado a indagar sobre la manera en que las homegirls se incluyen en el barrio o son incluidas. Las condiciones actuales dejan ver que esta inclusión de la mujer las atrae como víctimas de sus propias pandillas, sobre todo la $\mathrm{MS}_{\text {I } 3}$, en el marco de este proceso de institucionalización, nos dice Aguilar, «incrementa la violencia interna, la violencia intragrupo, entonces a eso también se atribuye todas esta serie de ejecuciones internas que se están dando, que cada vez son más duras, que tiene que ver ya con la disputa de negocios, con droga, cartera de extorsiones y conflictos de poder». La mujer pandillera, cada vez más incluida como víctima, se convierte en la parte más vulnerable de los procesos de reestratificación forzada mediante el endurecimiento de la persecución, incrementando la violencia más allá de las formas sangrientas, pues impulsa una descomposición interna que avisa explosiones virulentas:

Entonces, es grave, en donde la mujeres participan como parte de este fenómeno en su mayoría ya como víctimas, porque la mayoría participan colaborando y en un paso en falso, si hay un hecho que se puede calificar como traición, son asesinadas. Lo que vemos, pero esto sin tener base empírica, desde 2008 para acá es una descomposición interna de ese trance hacia la profesionalización, la corporativización criminal, hay una descomposición interna y a eso se debe el crecimiento exponencial de la violencia tanto interna como externa. Las divisiones entre ellos, las purgas internas, el descontrol. Entiendo que también los liberados se han fragmentado, entonces eso ha hecho que la violencia se incremente.

El efecto de reestratificación o corporativización, para utilizar el término de Aguilar, si bien produce una verticalidad en las pandillas, no opera ésta a favor de una recomposición orientada a lograr reinserciones o, siquiera, aperturas en el resto de la sociedad. Por el contrario, eleva las barreras simbólicas (ni que decir de las materiales) que aíslan a la pandilla del resto de la sociedad y viceversa. En esas dinámicas, las homegirls quedan aún más aisladas y margi- 
nadas, convirtiéndose en el fondo siniestro de las relaciones entabladas sólo a través de la acción policial y penal. «Eso es lo que estamos en estos momentos observando con lo que pasa con las mujeres — comenta Aguilar-, todos esos asesinatos que día a día estamos viviendo, mujeres asesinadas, desmembradas, abusadas también, en muchos de los casos sí son, parece ser que sí es la pandilla, la misma pandilla». La acción policial y penal estructuran de tal manera a las pandillas que producen un endurecimiento en su interior, la necesidad de sobrevivir y la búsqueda por eliminar a los contrarios, exigen al interior medidas desesperadas que permitan reforzar los vínculos. A esto se le suma la condición general que vive la mujer en El Salvador, convirtiéndola, simbólica y materialmente, en el eslabón más débil y prescindible: «porque la mayoría están presos, entonces, que su mujer vio a otro, que le habló a no sé quién, que anda con uno de la otra, o que tiene tratos con la otra pandilla, o sea, cualquier acción de estas mujeres, por acción o por omisión puede derivar en una ejecución»; y lo femenino en su conjunto se asume como entorpecimiento del proceso de fortalecimiento de la pandilla y las acciones violentas, con marca de violencia intrapandilla, se expande al resto de las localidades, al resto de la sociedad y «entonces tenemos muchas mujeres, muchachas que no están vinculadas a la pandilla, pero que han sido acosadas o que en algún momento han tenido contacto con amigos que tienen vínculos con las pandillas y ya eso las lleva a ser blanco de ejecuciones, hechos sanguinarios, han hecho cosas terribles", creando un efecto de exigencias sociales por recrudecer aún más las acciones policiales y penales, fortificando un círculo de violencia extrema. Las instituciones gubernamentales azuzan el fuego y las pandillas se incendian, extendiendo las flamas al resto de la sociedad.

En este sentido, Aguilar observa que los pandilleros, en sus acciones tendientes a reforzar su clausura simbólica respecto al resto de la sociedad han «retomado prácticas de los carteles mexicanos en las ejecuciones». Estas formas más crueles y simbólicamente más pesadas, funcionan también como elementos de vinculación con estructuras del crimen organizado. Se le preguntó a Aguilar si esto era como imitación, a lo cual respondió afirmativamente, para acotar enseguida «aunque bueno, sí se oye de que hay, que los están, hay reclutamiento de los cárteles de algunos de ellos y ha habido». Se insistió sobre el asunto, si tenía fuentes confiables que confirmaran el reclutamiento de pandilleros por parte de organizaciones criminales, particularmente los Zetas. A lo cual respondió sobre «una fuente periodística, sí, pero hay mucha de esta información que tampoco podemos verificar. Y de la policía que yo 
tengo información, porque la policía preventiva hace un seguimiento policial en cárceles, entonces, están prácticamente monitoreados y eso los ha llevado a incrementar las actividades». Esto complementa el testimonio arriba citado sobre el peligro del reclutamiento de pandilleros por parte de estructuras delincuenciales, sin embargo, como la misma Aguilar lo afirma, la posibilidad de confirmarlo es muy complicada, y lo cual, también confirma, la necesidad de comprender a las pandillas más allá de reestratificaciones y supuestas operaciones organizadas. La imitación en las ejecuciones responde más a formas de clausura y afirmación simbólica que incluyen a la pandilla contraria y a la exigencia de lealtad al interior, asunto cada vez más complejo frente a los conflictos intrapandilla también observados por Aguilar.

La acción policial y penal, sin otro tipo de acompañamiento institucional, produce aumento de violencia, no hay duda de ello. Tanta violencia impacta al interior de las pandillas y, más allá de debilitarlas o destruirlas, la deforma con rostros más fieros, ahora ya no tatuados, pero sí más paranoicos y temerosos del exterior que se les entremete:

Y ahora sí con algunos elementos para identificar a los soplones y asesinarlos, porque los están monitoreando, las composiciones, las llamadas, las reuniones que tienen, entonces eso ha llevado a elevar muchas de las capturas, pero además a sostener esta idea de que están vinculados mucho de ellos con la policía y mujeres sobre todo. Bueno, la semana pasada, no sé si te diste cuenta, pero decapitaron a la abuela, la mamá y la mujer que estaba embaraza, dicen que de un pandillero. Entonces el nivel de crueldad, de descomposición, nada que ver con los noventa.

\section{Estado penal}

En 2003, ante el aumento de la violencia entre pandillas, los Estados centroamericanos reaccionaron al fenómeno con políticas de mano dura o cero tolerancia, al puro estilo neoyorkino, eso sí, un tanto «tropicalizado». La cero tolerancia, como política policiaca y judicial, se implementa como modelo de gestión de la pobreza, es decir, de las masas pauperizadas, desheredadas o población «desecho», como la llama Bauman (I999). Desde Nueva York se expandió como política normativa de los espacios públicos a todo el mundo, como explica Wacquant: 
Se propagó a través del planeta a una velocidad fulminante. Y con ella la retórica militar de la «guerra» al crimen y de la «reconquista» del espacio público, que asimila a los delincuentes (reales o imaginarios), los sin techo, los mendigos y otros marginales a invasores extranjeros - lo cual facilita la amalgama con la inmigración, que siempre da réditos electorales-; en otras palabras, a elementos alógenos que es imperativo evacuar del cuerpo social (2008: 32).

Esta política de cero tolerancia se aplicó en Centroamérica con denominaciones como: Plan Mano Dura y Súper Mano Dura en El Salvador; Plan Escoba, en Guatemala; y Plan Libertad Azul en Honduras. En consonancia con el enfoque criminalizador y desciudadanizador (considerar patológicos y externos a los objetivos a perseguir, en este caso a los jóvenes pandilleros) se desplegaron con el principal objetivo de reprimir, ubicar y encarcelar. Para esto, precisaron de cambios en las leyes que permitieran dar tratamiento diferenciado a los pandilleros. Leyes de excepción que colocan a sujetos específicos, desde la raza o etnia hasta por la adscripción política, cada vez más disminuyendo las cualidades ciudadanas de los delincuentes, es decir, convirtiendo al delito en una forma de disminución de ciudadanía. Así, al considerar el movimiento entre fronteras sin documentación migratoria como un delito, se criminaliza al migrante y se le aplica una ley que lo coloca en estado de excepción, convirtiéndolo en un cuerpo vacío de ciudadanía, de derechos políticos, nuda vida (Agamben, 2003, 2004). No tienes sangre de mi sangre políticamente enriquecida, entonces eres perfecto para el horno, ya sea de maquila, ya sea de campo de verduras, ya sea en el turno nocturno de un tienda departamental, esclavo, sin alma ciudadana, sin nación, un puro nacer para el cañón de carne. La nuda vida queda apresada en tal fractura en la forma de la excepción, es decir de algo que sólo es incluido por medio de una exclusión» (Moreno, 2008: 19-20).

Si bien a comienzos de la década de 2000 se nota un aumento en los niveles de violencia y la tendencia hacia actividades delincuenciales más consuetudinarias entre los pandilleros (Santacruz y Concha-Eastman, 200I), con la introducción de cocaína y crack en el mercado salvadoreño, así como el aumento de los encarcelamientos y el consecuente encuentro de palabreros que promovió una verticalización, específicamente de la Pandilla i 8 , la mutación de reestratificación (jerarquización o corporativización, como la observa Aguilar) fue activada por la actitud criminalizante del Estado: la promulgación en 2003 del Plan Mano Dura como único esfuerzo gubernamental para enfrentar 
el fenómeno de las pandillas (Cruz, 2009). Orientación bélica, como apunta Wacquant (2008), contra una población alógena, patológica, venida de fuera, sin considerarse los procesos de su consolidación en El Salvador (Guerra civil-migración-deportación, la doble desterritorialización), sino sólo su forma monstruosa, espantosa. El rostro tatuado de los jóvenes pandilleros formó su imagen invasora y destructiva y, como mandan la doctrina neoyorkina de la cero tolerancia, los bárbaros venidos de fuera se utilizaron para ganar el apoyo de un público en shock, atenazado por el pánico moral, las campañas para las elecciones de 2004 se nutrieron con el discurso de la seguridad pública deformado en necesidades de seguridad nacional, lo que implica la asunción de un discurso militar. Esta modelación del enemigo inserto, más que interior, incluye a los medios de comunicación quienes amplificaron el discurso que convirtió a las pandillas, si no la única, sí la principal fuente de violencia y delincuencia en El Salvador. Una guerra al interior, pero no de corte civil, sino contra una fuerza delincuencial feroz. Una parte del cuerpo social ha sido infectada, para ello, es preciso componer la ley nacional de excepción. La llamada ley antimaras que permitió a la policía detener al azar y encarcelar a los jóvenes sospechosos de ser pandillero. Criminalizando el aspecto, la vestimenta y la edad, derruyendo el principio democrático de igualdad de derechos.

El Plan Mano Dura forzó una serie de reestratificaciones en las pandillas salvadoreñas debido a su aire de cero tolerancia como herramienta para gestionar la población excedente. Con redadas y detenciones masivas de pandilleros y sospechosos de ser miembros de pandillas. Con el encarcelamiento masivo de pandilleros, el sistema penitenciario salvadoreño, ya saturado, se sobrepobló aún más. Según reportes de 2005 de la Policía Nacional Civil, entre 2003 y 2005 , se capturaron 30.934 supuestos pandilleros. Según explican Jeannette Aguilar y Lissette Miranda (2006), la política de cero tolerancia salvadoreña se dividió en dos etapas: Mano Dura y Súper Mano Dura. En ambos los resultados se definieron por el volumen de arrestos, pero no por su eficacia, "se realizaron un total de I 8.800 capturas, en las que se detuvieron en varias oportunidades a los mismos jóvenes» (60), el plan tuvo como apoyo jurídico la llamada Ley Antimaras que duró i 80 días, pero «debido a que los jueces se negaron a aplicar la ley porque consideraron que contravenía la Constitución y los tratados internacionales», fue derogada. El Plan Súper Mano Dura, por su parte, se apoyó en la Ley para el Combate de Grupos y Asociaciones Ilícitas Especiales, muy parecida a la Ley Antimaras. Incluyó distintos operativos policiales: Puño de Hierro. «La operación Puño de Hierro contempló la iden- 
tificación de pandilleros, allanamientos de viviendas, capturas y patrullajes en zonas de presencia pandilleril, entre otros, durante los cuales la Policía Nacional Civil utilizó, de manera desproporcional, la fuerza y cometieron graves abusos a los derechos humanos» (6I). Durante este operativo, que duró de septiembre de 2004 a agosto de 2005 , la eficiencia en los arrestos no varió mucho a Mano Dura «la PNC capturó un total de I4.60I pandilleros, la mayoría reincidentes, pues han sido detenidos en reiteradas ocasiones» (62). Como adición, presentada como acompañamiento a los operativos exclusivamente policiacos y represivos, se presentaron los planes de corte social Mano Amiga y Mano extendida.

Respecto a esta adición tendiente a la reinserción y prevención, débiles con relación a la política represiva, es interesante el comentario del Viejo Lin en la entrevista que le realizaron Carlos Martínez y José Luis Sanz de elfaro.net (20II), cuando le preguntaron sobre el futuro del Barrio I 8 en El Salvador:

Negro, por decirlo de forma resumida. Aquí hay un sinfín de cipotes que se creen locos. La DEco la cagó. ¿Sabés por qué? Porque vino a contribuir con ellos para romper una estructura que tal vez le hubiera sido menos perjudicial al gobierno. No sé si me entendés. Yo como presidente o como ministro de Justicia todo el tiempo preferiría entenderme con alguien capaz de razonar. El Gobierno llegó con el plan Mano Amiga allá, a una colonia de Apopa; llevaban dos pliegos de Playwood que valen como 9 dólares lo mucho, dos cajitas de pintura y pinceles. Tenemos en esa colonia como a 50 miembros, con familias, hijos, esposas, etc... Andan tatuados, su capacidad de movimiento está limitada por la misma situación. ¿Creés que con hacer un muñequito al día y venderlo por dos dólares van a dar de comer a su familia? ¿Todavía creemos que dar solución a las rentas y la violencia es posible en base a lo que sabemos?

La orientación gubernamental a la tolerancia cero para el tratamiento del fenómeno de las pandillas transnacionales en El Salvador, que reventó con los planes Mano Dura y Súper Mano Dura, pero inició con la cárcel como único medio estatal para lidiar con el tema, claramente repercutió en la acidificación de las pandillas, en un recrudecimiento de la violencia debido a la verticalización orquestada desde la cárcel. El Viejo Lin es expresión de esto y parte de los resultados de esta política, pues la jerarquización de la pandilla, con el establecimiento de reglas internas más rígidas y con sanciones más brutales, 
implicó también la necesidad de controlar férreamente los territorios para el magro comercio de drogas y la extorsión, y amplificó la guerra entre la i 8 y la $\mathrm{MS}_{\text {I3 }}$. En 2004, debido a los acontecimientos en Mariona (centro penal La Esperanza, localizado en San Salvador), la Pandilla i 8 se desmembró en dos bandos (de lo que habla el Viejo Lin en su respuesta), acrecentando la violencia y los asesinatos. Como observan Aguilar y Miranda, la política de cero tolerancia implementada en El Salvador no disminuyó la violencia, la transformó al convertirla en algo más sistemático, gracias a la reestratificación que forzó en las pandillas.

El promedio diario de seis homicidios que se mantuvo hasta 2002 se ha elevado a I I en los últimos dos años, lo cual no sólo muestra el fracaso del Plan, sino el impacto directo de estas medidas en el incremento de la violencia homicida de los últimos años. Por otro lado, además de la exacerbación de la guerra entre pandillas, lo cual elevó los asesinatos de pandilleros, se reporta un aumento de asesinatos asociados a móviles patrimoniales (Aguilar y Miranda, 2006: 62).

El encarcelamiento masivo brindó inmejorable oportunidad para la verticalización de las pandillas (cómo de hecho ya había sucedido antes de las políticas de cero tolerancia), pues al reunirse bajo un mismo techo miembros del mismo barrio, pero dispersos territorialmente, palabreros de diversas clicas ensayaron estructuras jerárquicas. Pandilleros del mismo barrio establecieron contacto, se reconocieron otras clicas o canchas y así se permitió remodelar las pandillas con formas más estratificadas. Esto debido a la decisión de las autoridades de recluir a los pandilleros en centros penales distintos según su afiliación, MS I 3 о г 8, como renuncia, pues con esto denotaron su incapacidad para mantener el orden en los reclusorios y evitar los enfrentamientos entre pandillas y entre reos comunes y pandilleros.

La política de separarlos en función de su afiliación pandilleril, como forma de controlar la violencia que se genera en los centros reeducativos, ha sido duramente cuestionada por diferentes sectores y organizaciones. Estas señalan que esta medida ha fortalecido el accionar de las pandillas, en el sentido de que han reafirmado la identidad pandilleril y facilitado, en la práctica, una mejor organización y estructuración de las pandillas al concentrar en estos lugares a la membresía de la organización vinculada a 
hechos delictivos, lo cual ha facilitado la conformación de redes que operan en conexión con las pandillas territoriales (Aguilar y Miranda, 2006: 64).

Con esto, las políticas de mano dura permitieron reunión de clicas, canchas o tribus en un mismo lugar, facilitando comunicación y conexiones a nivel nacional. Se formaron así el Ruedo carcelero de la i 8 y la Ranfla de la MS I 3 .

El discurso militar se convirtió en la única voz del Estado para dirigirse a los jóvenes pandilleros reducidos a formas enemigas (casi virales). Discursos donde las pandillas se asumen como amenaza nacional, contra la cual ejercitar «una batalla frontal contra la delincuencia» y establecer «la línea de los que creemos en la seguridad de los ciudadanos y los que favorecen con argumentos de todo tipo a los delincuentes» (aludiendo, seguramente, a quienes criticaban la aplicación de legislaciones anticonstitucionales), y no dejan a los buenos ciudadanos (los únicos, aparentemente) pelear «contra los delincuentes y su terrorismo delincuencial» (El Diario de Hoy, 2003: I 2).

El discurso militar de guerra contra las pandillas, significa la apertura en términos del lenguaje para la desciudadanización de un sector específico de la población. Los pandilleros se convirtieron en enemigos jurídicamente establecidos, policialmente perseguidos y socialmente rechazados. Portadores de doble extranjería (aun cuando muchos jóvenes jamás hubieran dejado la nación salvadoreña), adquirieron cualidad de lo que Giorgio Agamben (2003) llama homo sacer, es decir, el sujeto que puede ser asesinado sin cometer delito, sin crimen, sin sanción. El discurso bélico dio la anuencia a actores extralegales, incluso agentes estatales, violación de derechos humanos fundamentales sin repercusiones, pues el efecto de la desciudadanización, es decir, la puesta en estado de excepción mediante la cancelación de derechos políticos.

El drama es que no hay drama, sino una pura gesticulación. El derecho no se esfuma, los derechos fundamentales de cualquier sujeto, aquello que le hace humano, sus derechos humanos, también van con él, pero, sencillamente, se suspenden frente al gesto biopolítico, pues el estado de excepción en el que se introduce le otorga su cápsula campo y sucede ese momento indiscernible pero fríamente sensible en que el sujeto se reduce a pura vida, a nuda vida. El sujeto se despoja de sujeción (de otredad) y se convierte en argumento, en cifra, en monigote listo para ser manipulado sin tapujos (Moreno, 2008: 24)

Esta asunción de una guerra contra las pandillas permitió la aparición de 
grupos armados de «limpieza social», actores civiles, como empresarios financiaron grupos ilegales y el desarrollo de una economía criminal de sicariato para acabar con los enemigos de la sociedad (Cruz, 2009).

\section{Desciudadanización}

Nietzsche, en el aforismo 235 de Humano, demasiado humano, dice: «El Estado es una astuta institución para la protección de los individuos unos contra otros: si se exagera su ennoblecimiento, acabará por debilitar, más aún, por disolver al individuo, es decir por frustrar de la manera más radical el fin originario del Estado» (Nietzsche, 2007: I 57). En términos de la teoría política hobbesiana (2003), el Estado surge para proteger al hombre de la otredad inmediata, cualquier otro hombre, siembre su lobo. La otredad Estado triangula la relación entre los seres humanos para evitar su destrucción mutua. Con Locke (2003) la triangulación es interiorizada a través de la ciudadanía, pues la relación con la otredad Estado deja de ser súbdito-soberano, para pasar a ciudadano-gobernante-que-a-su-vez-es-ciudadano. De esta manera se asientan las bases para el Estado moderno y el desarrollo de la democracia, donde el derecho de ciudadanía implica libertad e igualdad.

La desterritorialización forzada padecida por los salvadoreños durante la guerra civil y la segunda oleada en la década del 2000 por las condiciones económicas, influyó en la generación de un flujo de población móvil que dejó detrás la ciudadanía, primero como migrantes indocumentados, después ilegalizados por las legislaciones antiinmigrantes en Estados Unidos, es decir, convertidos en delincuentes sin derechos políticos (nuda vida), sellando la desciudadanización con las deportaciones masivas.

Como se ve en los cuadros 2 y 3 , conviven dos fuentes de datos, la primera serie es del Anuario de Estadísticas de Inmigración del 2007 de la Oficina de Estadísticas de Inmigración del Departamento de Seguridad Nacional de los Estados Unidos. Se puede observar un constante incremento de las migraciones hacia Centroamérica; a lo que se suma observación de Moncrief quien señala que «los países que recibieron el mayor número de deportados son México, seguido por El Salvador, Honduras y Guatemala, coincidiendo con los países más agobiados actualmente por las Maras» (2010: 73). La segunda serie deja ver cómo se comportó la deportación desde Estados Unidos en el caso exclusivo de El Salvador.

Con la deportación efectuada como sentencia, se opera no sólo una con- 
Cuadro 2. Deportaciones de Estados Unidos hacia Centroamérica de 1998 a 2007

\begin{tabular}{|c|c|c|c|c|c|c|c|c|c|}
\hline 1998 & 1999 & 2000 & 2001 & 2002 & 2003 & 2004 & 2005 & 2006 & 2007 \\
\hline 17.042 & 12.414 & 15.212 & 14.452 & 15.593 & 23.144 & 27.686 & 40.773 & 62.298 & 79.060 \\
\hline
\end{tabular}

Departamento estadounidense de Seguridad Nacional, Anuario de Estadísticas de Inmigración del año 2007, Oficina de Estadísticas de Inmigración. Datos tomados de Moncrief, 2010.

\section{Cuadro 3. Deportaciones de Estados Unidos hacia El Salvador de 2004 a 2011}

\begin{tabular}{|c|c|c|c|c|c|c|c|}
\hline 2004 & 2005 & 2006 & 2007 & 2008 & 2009 & 2010 & 2011 \\
\hline 6.248 & 7.117 & 14.395 & 20.111 & 20.203 & 19.209 & 18.734 & 15.400 \\
\hline
\end{tabular}

Datos tomados del Ministerio de Justicia y Seguridad Pública en http://www.seguridad.gob.sv/

versión del sujeto en un puro cuerpo movilizable como cargamento indeseado, sino que también se produce una doble desterritorialización que expulsa a la ausencia de pertenencia territorial, según la condición de ciudadanía bajo la ficción jurídica realizada en el ejercicio de los derechos políticos nacer-naciónnacionalidad-ciudadanía (Agamben, 200I) pues hay una disminución de la condición ciudadana, una desciudadanización oculta en la degradación del sujeto a una forma distinta (si bien no necesariamente inferior, aunque está implícito, si una forma animalizada, desocializada, marginada), una criminalización de la no ciudadanía pues, "nunca habían cometido delitos en el país, jamás habían cumplido una condena, nadie los había discriminado por los tatuajes, simplemente los deportaron por ser jóvenes y no tener documentos. $\mathrm{Al}$ parecer el hecho de estar indocumentados los hacía delincuentes» (Goubaud, 2009: 7). Como comenta Derrida en Canallas, descifrando el significado del canalla desde el francés «Voyou no vendría de voie, vía, como dévoyé, embaucador, o dévoiement, embaucamiento, sino, por alteración o desviación, de voiron, que se decía en lugar de loup-garou, de 'hombre lobo'» (2005: 9I), el fuera de la ley es un animal, "ha ocurrido que se tradujese en inglés la palabra loup-garou, en la Confesiones de Rousseau, no por werwolf, sino por outlaw (fuera de la ley)», es decir, una forma no social y difícilmente domesticable que debe ser tratada como maleza, muy en consonancia con la definición jurídica de los nativos americanos en la Constitución política de los Estados Unidos, como afirman Hardt y Negri en Imperio:

Así como es necesario despejar el territorio de árboles y rocas para convertirlo en terreno laborable, hay que expurgarlo de sus habitantes nativos 
[...] Para los colonizadores, los nativos norteamericanos eran meramente un elemento más de la naturaleza, particularmente espinoso al que había que expulsar y/o eliminar mediante una guerra continua [...] Si se los hubiera reconocido, no habría habido ninguna frontera real en el continente ni espacios abiertos para ocupar. Los nativos existían fuera de la Constitución como su sustento negativo: en otras palabras, excluirlos y eliminarlos eran condiciones esenciales del funcionamiento de la Constitución misma (2002: I63).

Esta desciudadanización es efecto del segundo movimiento de desterritorialización producto de las deportaciones, una violencia efectuada en la exclusión y el desarraigo al que los jóvenes deportados se encuentran cuando retornan al país de origen sin mucho que los vincule en él. Con la deportación quedan sin contacto con familiares, sin reconocer el lugar al que han sido enviados, tierra a la que no pertenecen. En muchas ocasiones, cuando son miembros de alguna pandilla y no regresan a su país para ir directo a la cárcel, los homeboys son sus únicas fuentes de seguridad y, al mismo tiempo, la marca que los pone en peligro. Luis Romero, director de Homies Unidos El Salvador explica que el peligro al que se enfrentan los pandilleros deportados es mortal, «recolecto las actas de defunción de los que entraron y murieron. Mantengo de emeeses, dieciochos que han muerto para sustentar casos en los Estados Unidos, para que no deporten gente, para hacer constar que la deportación de jóvenes de pandillas es ponerlos en una situación de riesgo total, de muerte total». Por otro lado, las oportunidades de trabajo y estudio son casi inexistentes. En este caso, el mismo Luis Romero de Homies Unidos explica cómo actúa la organización para encontrar oportunidades de empleo a los jóvenes recién llegados:

Nosotros como organización hemos pensado en microempresas, bueno, tenemos también la cosa de los call centers, que sabemos que es una explotación laboral, porque un call center en Estados Unidos le están pagando a un joven como de 22 a 25 dólares la hora, en El Salvador le pagan 4 dólares la hora, pero es una forma más digna de vivir. Estamos ahorita metiendo a gente en call centers como los deportados. Vienen deportados de Estados Unidos y pueden inglés, pero no pueden computación, entonces ahí vengo con mi proyecto de educación técnico vocacional, les doy una beca para que vaya a aprender computación y ya, con el inglés que tiene y su computación, insertamos laboralmente a alguien. 
Sin embargo, la capacidad de Homies Unidos es mínima comparada con el flujo de población deportada, sin abundar en la dinámica perversa que implica el outsourcing promovido por la flexibilización productiva e internacional del sector servicios global (mano de obra barata para disminuir los costos de la fuerza laboral).

Así pues, además de las leyes de excepción, claramente desciudadanizantes al contravenir lo más elemental de los derechos ciudadanos, está la imposibilidad de los gobiernos para cumplir lo establecido por las Constituciones que los instauran, donde se establece el derecho de todo ciudadano a que el Estado garantice la seguridad nacional y personal.

\section{Conclusiones}

La politización de lo impolítico de la pandilla a través de la criminalización destruye las cualidades positivas de su línea de fuga como acción creativa. Su capacidad destructiva es amplificada por la acción represiva, desciudadanizadora. En ese cruce la pandilla tiende a la huida hacia el hoyo negro y se elimina la posibilidad de vislumbrarla como una forma de colectividad legítima y enriquecedora para los jóvenes. Si bien la violencia es parte integral de su pertenencia absoluta, aplicarle más violencia no permite pensarla como alternativa de orientación social, de liberación social y tiene ese germen, esterilizado tanto por su violencia como por la violencia legal que se le aplica. Sin embargo, también está latente en el lazo-de-deuda, en la subjetividad explosiva que propone, en ese volcarse al otro sin vergüenza, culpa o asco, una subjetividad ligada, no aislada como la esférica.

El estado de excepción se produce para aislar a un sector social amenazante, ya sea real o imaginario (con esto no se disminuye la capacidad de violencia que tienen las pandillas transnacionales, sólo se pretende observarlas más allá de la visión criminalizante), capaz de destruir, y no sólo desestabilizar, las instituciones y valores socialmente establecidos. Así, el Estado, ya con el elemento patógeno identificado, tiene un aval para la implementación de acciones coercitivas para desactivar la amenaza. Para esto, se supone la anuencia de la sociedad buena para instaurar estados de excepción localizados, es decir, no en todo el territorio, no sobre la población, sino sobre los individuos o sectores identificados como amenazantes. En el caso que nos ocupa, las pandillas son sometidas a estados de excepción dirigidos mediante artilugios legales que desactivan sus derechos para aplicar una considerable dosis de discrecionalidad 
de fuerza bajo la fuerza de la ley. Se desciudadaniza al enemigo y se le declara la guerra que debe ser de exterminio para ser eficaz. El asunto es que el enemigo está dentro y no ha declarado la guerra contra el gobierno o la sociedad, nunca se ha ido, aunque se encuentre al margen y a pesar de la doble marginalización que padecen los jóvenes pandilleros, quienes no enarbolan bandera ideológica alguna, quienes asumen al gobierno como enemigo en la medida en que son convertidos en el enemigo número uno del orden y la seguridad. La marginalización arrecia y la violencia aumenta.

Esta producción de, digamos, burbujas de excepción, ahí donde el cuerpo del pandillero, por el hecho de ser o parecer, queda aislado de los derechos políticos, es posible en países democráticos gracias al ejercicio de leyes desciudadanizantes, al uso parcial del derecho y la creación de un bando enemigo que perfila la batalla. Los bandos entran en pugna unilateralmente bajo el entendido de que los enemigos ya han declarado la guerra: los ciudadanos contra los delincuentes y, obviamente, sus defensores, empecinados en considerar a cualquier ser humano como portador de derechos, políticos y humanos. La guerra, la batalla frontal, donde se incluye al ejército como fuerza de tarea en el propio territorio y contra sus conciudadanos (sin existir una beligerancia redundante en guerra civil) se declara, disminuyendo, sino es que de plano eliminando, la ciudadanía de unos.

La aplicación de políticas públicas militares como el plan Mano Dura y Súper Mano Dura es idéntica a la doctrina de la seguridad nacional, pivotada por la presencia de fuerzas internas insurgentes, revolucionarias, contrarias al gobierno, incluso al Estado. La seguridad pública confundida con seguridad nacional impone la necesidad de orientar el combate a la inseguridad y a la delincuencia mediante mecanismos que suspenden el estado de derecho, la organización de aparatos públicos que selectivamente crean estados de excepción desde el cuerpo de los condenados (social, económica, política y, con esta estrategia, penalmente). Como se observa en la modelación del enemigo ensayada en los locales de la inteligencia militar para la seguridad nacional (para el caso es elocuente el título del artículo «The new urban insurgency» de Max G. Manwaring), se piensa en términos de guerra civil contra un enemigo, más imaginario que real en cuanto a sus motivaciones, que no puede ser eliminado sin dañar profundamente al resto de la sociedad. Muy al contrario, ese enemigo modelado llega a cumplir la profecía diseñada por el discurso que la presenta al público.

En el artículo citado de Manwaring (2005), el enemigo, en este caso las 
pandillas, aparece como una fuerza capaz de desestabilizar al Estado, incluso capaz de imponer uno nuevo, como si se tratara de fuerza revolucionaria con programa político e ideológico, pero con una motivación puramente económica (salvajismo del capital, quizá). En su análisis de las pandillas observa tres niveles de evolución hacia la amenaza política y social, según tres generaciones.

- La primera generación —o pandillas tradicionales callejeras- son el primer germen. Tienen un liderazgo flexible y poco sofisticado y centran su atención en la protección del territorio para obtener efectivo para gastos menores y en la lealtad pandillera dentro de su entorno inmediato (cuadras o barrios). Cuando las pandillas de primera generación comienzan a participar en actividades criminales es, en gran medida, de manera oportunista e individual (no interviene el grupo), es una participación localizada y opera en el extremo inferior de la violencia extrema, el pandillerismo y bandolerismo. La mayoría de los grupos permanecen en esta etapa de desarrollo, pero algunas pandillas se han desplazado a la segunda generación ( 5 , traducción nuestra).

- Esta generación de pandillas se organiza para obtener beneficios económicos. Tienen un liderazgo más centralizado, y se concentran en el tráfico de drogas y la extorsión. Al mismo tiempo, operan en áreas geográficas más amplias, que pueden incluir ciudades vecinas y otros Estados de la nación. Las pandillas de segunda generación, como otras empresas criminales más sofisticadas, utilizan la violencia para proteger sus mercados y controlar a su competencia. También utilizan la violencia como interferencia política para repeler los esfuerzos de seguridad de la policía y otras organizaciones de seguridad. Y en su intento por controlar o incapacitar a las organizaciones de seguridad del Estado, a menudo comienzan a dominar la vida de la comunidad vulnerable dentro de grandes áreas del Estado-nación. En este entorno, las pandillas de segunda generación tienden a vincularse con organizaciones delictivas transnacionales para brindarles servicios. En este contexto, han sabido desarrollarse para orientarse al mercado, y en ocasiones con agendas abiertamente políticas para mejorar su cuota de ingresos. (I6, traducción nuestra).

- Estas pandillas continúan con las acciones de las de primera y segunda generación a medida que expanden sus parámetros geográficos, así como sus objetivos comerciales y políticos. A medida que evolucionan, 
se desarrollan en organizaciones más experimentadas, con mercados más amplios relacionadas con la droga, como las muy sofisticadas organizaciones criminales transnacionales con ambiciosas agendas políticas y económicas. En este sentido, inevitablemente empiezan a controlar territorios sin gobierno dentro de un Estado-nación y/o comienzan a adquirir poder político en los espacios mal gobernados (I7, traducción nuestra).

La profecía se cumple en su redacción. La implementación de políticas desciudadanizantes, que recrudecen la marginación, imponen presión para producir reestratificaciones forzadas tendientes a la violencia, pero con un objetivo más claro y amplio que, en este caso, la pandilla contraria. La criminalización excluye incluyendo como enemigo a un sector de la sociedad que, al ser delineada de esta forma, reacciona con mayor agresividad. Como señala Jeannette Aguilar (2004), los datos sobre el comportamiento de los homicidios en el periodo de aplicación de los planes del manodurismo superaron en números al periodo inmediatamente posterior. El aumento de los encarcelamientos permitió la conformación del Ruedo de la i 8 y la Ranfla de la MS (Cruz, 2009). Se dañaron los derechos humanos y políticos de muchos jóvenes que, sin otras oportunidades, reviraron violentamente.

Es innegable que en los últimos años los factores políticos institucionales relacionados con la respuesta del Estado han contribuido enormemente a complejizar la dinámica de las pandillas. Si bien se reconoce que desde inicios de 2000 se advertía entre éstas importantes transformaciones relacionadas con un mayor ejercicio de la violencia, incremento en el consumo de drogas y mayor uso de armas de fuego, el salto cualitativo más importante en la dinámica pandillera es el que se registra en el contexto de los planes antipandillas impulsados por el Gobierno salvadoreño a partir de 2003 [...] que se perfila como una nueva modalidad de organización criminal, responsable de generar una importante cuota de violencia en el país [con] transformaciones importantes en la imagen y el estereotipo tradicional asociado a los pandilleros; transformaciones orientadas a dificultar su identificación y a garantizar una mayor clandestinidad en su accionar (Aguilar, 2007: 879).

En la actualidad, la reestratificación forzada por las políticas criminalizantes ha provocado un aumento de la violencia que incluye la división de la 
Pandilla I 8 en Revolución y Sureños, motivada por la jerarquización venida de los centros penales. La violencia se ha tornado cada vez más cruenta, pasando por encima de los códigos de la pandilla al afectar directamente a quienes les rodean, como una reacción para mantener cerrado y seguro al grupo. La actitud policiaca no ha mejorado en la investigación de los delitos, pues con los pandilleros tienen al mejor chivo expiatorio. No se resuelven crímenes, pero se capturan pandilleros una y otra vez hasta el hostigamiento, el resentimiento genera al enemigo. La opción de crear prisiones de máxima seguridad donde se aísla a los elementos considerados más peligrosos también ha provocado reacción en los pandilleros, aunque menos violenta, como las marchas realizadas en 2009 y 2010 para exigir mejores condiciones penitenciarias (donde Homies Unidos cumplió un papel relevante como instancia para permitir el diálogo entre pandilleros y el gobierno). Pero también están los hechos del 9 de septiembre de 20 Io cuando ambas pandillas $\left(\mathrm{MS}_{\text {I } 3}\right.$ y I 8 ) protestaron contra la Ley de Proscripción de Maras amenazando a transportistas y comerciantes para establecer una paro de labores. La violencia va en aumento, a tal grado que en marzo de 20 I 2 se trasladó a miembros de la MS I 3 y I 8 del penal de máxima seguridad de Zacatecoluca a un centro de mediana seguridad. Esto ha hecho pensar en un pacto entre el gobierno salvadoreño y las cúpulas carcelarias de las pandillas para frenar los homicidios, pues éstos disminuyeron drásticamente en esas fechas, como señala el artículo «Gobierno negoció con pandillas reducción de homicidios» del sitio elfaro.net (Martínez, Arauz, Lemus, 20I2). Más allá de si esto es una negociación entre Gobierno y palabreros de las pandillas, pues el traslado fue realizado conforme a la ley, donde se define que el cumplimiento de la pena en centros de máxima seguridad es una medida excepcional (Pineda, 20I2). El ambiente calmo que priva actualmente en El Salvador, para convertirse en una constante y no sólo algo excepcional, precisa de una perspectiva que supere la tentación criminalizante y que opte por formas integrales de enfrentamiento al fenómeno de las pandillas, sin pretender eliminarlas, sino buscar formas donde éstas sean integradas a las dinámicas virtuosas de la sociedad, más allá de la actividad delictiva y violenta de las pandillas, debe existir algo en ellas capaz de brindar a los jóvenes espacios de socialización comunitarios que les permitan soportar y superar las condiciones de marginalidad.

Como expresa un joven pandillero activo:

Cuando a uno lo conocen es distinto, pero aquí nosotros respetamos 
a cualquiera, nunca dañamos a la gente así, pero como a veces los confunden con detectives, y así. Aquí es tranquilo man, aquí pueden venir las veces que quieran y aquí siempre van a ser bienvenidos. Aquí no hay bronca, que los vamos a extorsionar que les vamos a quitar el dinero. Que es lo que otra gente cree. Aquí vino una italiana, estuvieron ahí y dijo me quiero tomar una foto con ustedes, quiero en que en mi país vean, dijo, de que estuve con ustedes y no me hicieron nada, quiero que vean sus tatuajes y todo tatuado, no me robó, no me violó no me pegó, vea, a lo que en otro país cree otra gente. La delincuencia está en todos los países, pero otro país dice veamos los factores de otro país, no puedo barrer la casa del amigo si no he barrido la mía. Esto que usted está haciendo, que dice usted que va a sacar algo vea, si usted lo escribe o si usted lo narra o no sé, no se le olvide poner ahí men, que usted de su parte tomo en cuenta que nosotros somos humanos y creemos en un dios y en la justicia terrenal y celestial y que también tenemos derecho a vivir. Que quede claro que la delincuencia no la hemos formado nosotros, la delincuencia la ha formado el que tiene dinero, desde que él empezó a robarle al pobre y el pobre le robo a otro pobre y así se vino saliendo. Es necesario que la gente sepa de que la maldad men, viene desde Caín y Abel el primer homicidio que hubo, vea. Usted ha leído la biblia, vea. Caín y Abel, Caín mató a su hermano, ese fue el primer homicidio y de ahí se vino lo demás.

\section{Pensar diferente}

El presente trabajo es parte de una investigación sobre formas de reestratificación desde la sociedad civil. Dicha investigación lleva por título «Estrategias de reestratificación desde la sociedad civil: el caso Homies Unidos». En este sentido, este artículo aborda sólo la dimensión de las estrategias institucionales para el tratamiento del fenómeno de las pandillas transnacionales, lo que hemos definido como reestratificación forzada. Se observa cómo estas estrategias producen mayor violencia, sin presentar opciones organizativas orientadas a mejorar la vida de los jóvenes pandilleros, sin buscar crear formas sociales productivas en el sentido de asegurar a los jóvenes marginales instancias de resistencia a los influjos del sistema capitalista que los excluye.

La investigación en su conjunto presenta cómo se inserta la organización no gubernamental Homies Unidos, quien promueve la acción no violenta y la 
vocación de no violencia que le ánima vincula a los pandilleros con el resto de la sociedad sin que se les exija salir de la pandilla, es decir, Homies Unidos entiende a la pandilla como una instancia desde donde los jóvenes pueden desarrollarse al encontrar en ella sustentos simbólicos y materiales que no hallan en sus entornos sociales inmediatos. Una forma de presentar la filiación pandillera más allá de los contornos destructivos que el imaginario social empata con la pertenencia a estos grupos, esto sin dejar de observar que la violencia es profunda y constante en el existir pandillero. La manera de acometer el fenómeno por parte de Homies Unidos nos parece una forma de pensar diferente la problemática y presenta sugestiones válidas para ser replicadas. No es el motivo del presente artículo ahondar en el tema, sino dejar claro cómo las estrategias hasta hoy esgrimidas no han funcionado para aliviar los malestares producidos por la marginación y empobrecimiento y cómo las formas de resistencia social se han convertido, por sí mismas, en articulaciones susceptibles de ser criminalizadas sin problematizar su lado positivo, aquel que podría dejar emerger formas de organización social capaces de convertirse en espacios sociales impulsadores de formas distintas de vida. En ese sentido es que problematizamos en este artículo la acción desciudadanizadora de las estrategias criminalizantes, asumiendo que la portación de ciudadanía, en las democracias contemporáneas y en el entorno de globalización económica donde las ciudadanías aún se sostienen por su vínculo con la relación nacer-nación, es un asunto también por problematizar, pero que para la materia de este artículo excede los objetivos. En la investigación donde se inscribe lo presentado aquí, la ciudadanía como herramienta política y subjetiva para exigir y luchar por la exclusión política y social está presente y es con la figura de Homies Unidos donde hallamos una trinchera para los pandilleros donde se podrían construir las condiciones para disminuir la violencia.

En resumen, lo aquí presentado pretende coadyuvar a la producción de un pensamiento diferente respecto al fenómeno de las pandillas transnacionales. Una exigencia hecha por los mismos pandilleros, "pensar diferente» (y una convicción de los autores desde que se inicio con el proceso de investigación con pandillas desde 2003, en específico el dr. Hugo César Moreno Hernández, en las investigaciones para obtener los grados de Maestro en Sociología y Doctor en Ciencias Sociales y Políticas). A este respecto, valga el punto número 8 del comunicado presentado por los voceros nacionales de la Mará Salvatrucha I 3 y La Pandilla I8, publicado el I9 de marzo de 20 I2, con el motivo de aclarar la tregua entre ambas pandillas, iniciada en marzo de 20I2, específicamen- 
te la petición que hacen los pandilleros a los académicos e investigadores, lo cual incluye un llamado a pensar diferente:

A los que viven de hacer análisis les invitamos a renovar el esquema con el que analizan nuestro fenómeno, mientras nos sigan analizando sólo como fenómeno delincuencial sus análisis serán erróneos y de igual manera sus recomendaciones para resolverlo, es necesario que entiendan de una vez por todas, que somos un fenómeno social y que la guerra que nos hemos visto obligados a librar, tiene causas socioeconómicas y por tanto su solución no solo es legal y de represión sino también con medidas sociales y económicas.

También, estamos convencidos de que problematizar el lado positivo de la dicotomía ciudadanía-no ciudadanía o desciudadanización como proceso de disminución de derechos ciudadanos, es un asunto central en la reflexión sobre nuestras sociedades. Sin embargo, es un tema que por sí solo representa una empresa importante, imposible de abordar aquí con todas sus aristas y complejidades.

\section{Referencias}

Agamben, Giorgio (200I). Medios sin fin. Notas sobre la política. Valencia: Pre-Textos.

-. (2003). Homo sacer. El poder soberano y la nuda vida. Valencia: Pre-Textos.

-. (2004). Estado de excepción. Homo sacer II, 1. Valencia: Pre-Textos.

Aguilar, Jeannette (2004). «El manodurismo y las “políticas” de seguridad». En Materiales de Discusión, 20, publicación de la Asociación Yek Ineme, enero.

-. (2007). «Los resultados contraproducentes de las políticas antipandillas». En ECA Estudios Centroamericanos, 62 (708): 87 I-890.

Aguilar, Jeannette y Marlon CARranza (2009). «Las maras como actores ilegales en Centroamérica». En Gino Costa y Carlos Romero (editores), ¿¿ué hacer con las pandillas? (pp. I I-I49). Lima: Ciudad Nuestra.

Aguilar, Jeannette y Lissette Miranda (2006). «Entre la articulación y la competencia: las respuestas de la sociedad civil organizada a las pandillas en El Salvador». En J. M. Cruz (editor), Maras y pandillas en Centroamérica. Las respuestas de la sociedad civil organizada. San Salvador: UCA Editores. 
Bauman, Zigmunt (I999). Globalización, consecuencias humanas. México: Fondo de Cultura Económica.

Cruz, José Miguel (2009). Global Gangs in El Salvador: Maras and the Politics of Violence. Paper presented at the Global Gangs Workshop, Centre on Conflict, Development, and Peacebuilding, Geneva, May I4-I 5 .

DerRIDA, Jaques (2005). Canallas. Dos ensayos sobre la razón. Madrid: Trotta. El Diario de Hoy (2003). Domingo 3 de agosto, p. I2.

Goubaud, Emilio. (2009). Maras y pandillas en Centroamérica. Serie Policy Briefs, I, septiembre, Consorcio Global para la Transformación de la Seguridad. Disponible en <http://www.securitytransformation.org/esp/gc_publications>.

Hardt, Michael y Antonio Negri. (2002). Imperio. Buenos Aires: Paidós.

Hobbes, Thomas (2003). El Leviatán. México: Fondo de Cultura Económica.

Instituto Universitario de Opinión Pública (20Io). Segundos en el aire: mujeres pandilleras y sus prisiones. San Salvador: IUDOP-UCA-Cordaid.

Locke, John (2003). Ensayo sobre el gobierno civil. México: Gernika.

Manwaring, Max G. (2005). Street gangs: the new urban insurgency. Standard Form 298 (Rev. 8-98).

Martínez, Óscar, Carlos Martínez, Sergio Arauz y Efren Lemus (2012). «Gobierno negoció con pandillas reducción de homicidios». En <http:// www.elfaro.net/es/201 203/noticias/7985/>

Moncrief, Haley M. (2010). Seguridad nacional y hemisférica en la era de la interdependencia: La emergente amenaza de la Mara Salvatrucha. Universidad de Chile, Instituto de Estudios Internacionales. Tesis para postular al Magister en Estudios Internacionales, Santiago, Chile.

Moreno, Hugo César (2008). «Profanación a la biopolítica: a propósito de Giorgio Agamben». Iberoforum, 3 (6): I 5-36.

-. (20I I). La pandilla como ejercicio de micropoder. Relaciones de poder en los márgenes de la sociedad, jóvenes, violencia y estrategias de sobrevivencia. Editorial Académica Española.

-. (2010). La mara como ejercicio de contrapoder. Universidad Iberoamericana, Tesis de Doctorado, México.

Moreno, Hugo César y Mónica Sánchez (20I2). «La pandilla como cuerpo sin órganos». Metapolítica, 77: 77-86.

Nietzsche, Friedrich (2007). Humano, demasiado humano. Madrid: Akal.

Organización de las Naciones Unidas (2007). Crimen y desarrollo en 
Centroamérica. Atrapados en una encrucijada. Eslovaquia, Oficina contra la Droga y el Delito.

Perea, Restrepo Carlos Mario (2007). Con el diablo adentro. Pandillas, tiempo paralelo y poder. México: Siglo xxi.

Pineda, Óscar (20I2). "Asuntos destacables sobre el tema del pacto entre pandillas». La Prensa Gráfica, domingo 25 marzo de 20I2, disponible en $<$ http://www.laprensagrafica.com/opinion/editorial/25 5 I 79--asuntos-destacables-sobre-el-tema-del-pacto-entre-pandillas.html>.

Santacruz, María, y Alberto Concha-Eastman (200I). Barrio adentro. La solidaridad violenta de las pandillas. San Salvador: IUDP-UCA/OPS-OMS.

SAntamaría, Balmaceda Gema (s/f). "Maras y pandillas: límites de su transnacionalidad». En Revista Mexicana de Política Exterior, 8I, disponible en $<$ http://portal.sre.gob.mx/imr/popups/articleswindow.php?id=I69>.

Wacquant, L. (2008). Las cárceles de la miseria. Buenos Aires: Manantial.

\section{Sobre los autores}

Hugo César Moreno Hernández es Doctor en Ciencias Sociales y Políticas de la Universidad Iberoamericana. Su correo electrónico es <hcmor@hotmail>. Mónica SÁnchez González es maestra en historia, estudiante de Doctorado en Ciencias Sociales y Políticas, Universidad Iberoamericana, Ciudad de México. Su correo electrónico es <monicaelivier@hotmail.com>.

Este artículo es resultado del proyecto ganador de la Primera Convocatoria de Investigación e Innovación dirigida a Prestadores de Servicios Profesionales Docentes de la Universidad iberoamericana, Ciudad de México, que lleva por título «Estrategias de reestratificación desde la sociedad civil: el caso Homies Unidos». 